\title{
Brief report: Tracheal intubation using the Bonfils intubation fibrescope or direct laryngoscopy for patients with a simulated difficult airway
}

\author{
[Compte-rendu court: L'intubation trachéale à l'aide du fibroscope d'intubation Bonfils ou la laryn-
} goscopie directe pour le traitement de patients présentant des voies aériennes difficiles simulées]

Christian Byhahn MD, ${ }^{*}$ Sebastian Nemetz, ${ }^{*}$ Raoul Breitkreutz MD, ${ }^{*}$ Bernhard Zwissler MD, ${ }^{*}$ Manfred Kaufmann MD, $\dagger$ Dirk Meininger MD*

Background: The Bonfils intubation fibrescope (BIF), a rigid, straight and reusable fibreoptic device, is being used increasingly to facilitate endotracheal intubation after direct laryngoscopy has failed. We tested the hypothesis that, with the BIF compared to direct laryngoscopy, the rate of failed endotracheal intubation could be reduced in patients with a difficult airway, simulated by means of a rigid cervical immobilization collar.

Methods: Seventy-six adults undergoing elective gynecological surgery under general anesthesia were randomly assigned to have endotracheal intubation, facilitated with either a standard size 3 Macintosh laryngoscope blade, or the BIF. A rigid cervical immobilization collar was used to simulate a difficult airway, by reducing mouth opening and limiting neck extension. If endotracheal intubation could not be achieved within two attempts, the cervical collar was removed, and direct laryngoscopy was performed thereafter, using a Macintosh blade in all subjects. The success rate of endotracheal tube placement was the primary outcome variable.

Results: Patient characteristics were similar in the two groups. After neck immobilization, the inter-incisor distance was reduced to $2.6 \pm 0.7 \mathrm{~cm}$ (Macintosh) and $2.6 \pm 0.8 \mathrm{~cm}$ (BIF). Tube placement was successful in I5/38 (39.5\%) patients with a Macintosh blade, and in $3 \mathrm{I} / 38$ patients with the BIF (8I.6\%; $P$ $=0.0003)$. Time required for tube placement was $53 \pm 22 \mathrm{sec}$ (Macintosh) and $64 \pm 24 \mathrm{sec}$ (BIF; $P=0.15$ ).

Conclusion: The Bonfils intubation fibrescope is a more effective intubating device for patients with immobilized cervical spine and significantly limited inter-incisor distance, when compared to direct laryngoscopy.
CAN J ANESTH 2008/55: 4 / pp 232-237

Contexte : Le fibroscope d'intubation Bonfils (BIF) est un appareil fibroscopique rigide, droit et réutilisable qui est de plus en plus utilisé pour faciliter l'intubation endotrachéale lors de l'échec d'une laryngoscopie directe. Nous avons testé l'hypothèse que lorsque le BIF est comparé à la laryngoscopie directe, le taux d'échec de l'intubation endotrachéale pouvait être réduit chez des patients présentant des voies aériennes difficiles, lesquelles ont été simulées grâce à un collier d'immobilisation cervicale rigide.

Méthode: Soixante-seize adultes devant subir une chirurgie gynécologique programmée sous anesthésie générale ont été randomisées à recevoir une intubation endotrachéale, facilitée soit par une lame de laryngoscope Macintosh de taille standard 3 ou par le BIF. Un collier d'immobilisation cervicale rigide a été placé pour simuler des voies aériennes difficiles en réduisant l'ouverture de la bouche et en limitant l'extension du cou. Si l'intubation trachéale ne réussissait pas après deux essais, le collier cervical était retiré et une laryngoscopie directe réalisée ensuite à l'aide d'une lame Macintosh chez toutes les patientes. Le critère d'efficacité principal était le taux de positionnement correct de la sonde endotrachéale.

Résultats : Les caractéristiques des patientes étaient similaires dans les deux groupes. Après immobilisation du cou, l'espace entre les incisives a été réduit à 2,6 $\pm 0,7 \mathrm{~cm}$ (Macintosh) et 2,6 $\pm 0,8$ $\mathrm{cm}$ (BIF). La sonde a été placée correctement chez 15/38 (39,5\%) patientes avec une lame Macintosh et chez $31 / 38$ patientes avec le BIF (8I,6\%; $P=0,0003)$. Le temps requis pour le positionnement

From the Departments of Anesthesiology, Intensive Care Medicine, and Pain Management, ${ }^{*}$ and Gynecology and Obstetrics, $\dagger$ J.W. Goethe-University Medical School, Frankfurt/M, Germany.

Address correspondence to: Dr. Christian Byhahn, MD, Department of Anesthesiology, Intensive Care Medicine, and Pain Management, J.W. Goethe-University Medical School, Frankfurt/M, Theodor-Stern-Kai 7, D-60590 Frankfurt, Germany. Phone: +49-69-6301 5513; Fax: +49-69-6301 5881; E-mail: c.byhahn@em.uni-frankfurt.de

Conflict of interest: The Bonfils intubation fibrescopes were provided on a complimentary basis by Karl Storz GmbH and Co. KG,

Tuttlingen, Germany. There were no other sources of funding. None of the authors has any conflicts of interest related to the products and/or companies mentioned in the manuscript.

Accepted for publication October 9, 2007.

Revision accepted January 24, 2008.

Final revision accepted January 28, 2008. 
de la sonde était de $53 \pm 22 \mathrm{sec}$ (Macintosh) et $64 \pm 24 \mathrm{sec}$ (BIF; $P=0,15)$.

Conclusion: Comparé à la laryngoscopie directe, le fibroscope d'intubation Bonfils est un appareil d'intubation plus efficace pour les patients ayant la colonne cervicale immobilisée et un espace entre les incisives considérablement limité.

$\mathrm{P}$ ATIENTS with an unanticipated difficult airway requiring endotracheal intubation, remain an ongoing challenge for anesthesiologists and emergency physicians. If direct laryngoscopy fails, various supraglottic devices can be used to establish an artificial airway, according to the American Society of Anesthesiologists' difficult airway algorithm. ${ }^{1}$ For some patients, however, endotracheal intubation is crucial to securing the airway, protecting the lungs from aspiration of gastric contents, and for managing patients in the prone position. In addition to flexible fibreoptic bronchoscopy, and the less commonly used Bullard ${ }^{\circ}$ (Circon ACMI, Stamfort, CT, USA) and Wu® (Achi Co., San Jose, CA, USA) scopes, other devices are used with increasing frequency for endotracheal tube placement in patients with potentially challenging intubating conditions. For example, due to cervical spine immobilization, the intubating laryngeal mask (ILMA)® (LMA Deutschland GmbH, Bonn, Germany) allows blind insertion of an endotracheal tube, ${ }^{2}$ while the Trachlight ${ }^{\circledR}$ stylet (Laerdal Medical Co., Wappingers Falls, NY, USA) facilitates intubation based upon the principle of transillumination of the soft tissues of the neck. ${ }^{3,4}$ Devices which apply the principle of indirect visualization of the laryngeal structures include the GlideScope ${ }^{\circledR}$ (Verathon Inc., Bothell, WA, USA), a video laryngoscope with a digital camera located at the blade tip, and a small, separate LCD-monitor connected to the laryngoscope handle with a short cable. ${ }^{3,4}$ The rigid Bonfils $®$ intubation fibrescope (Karl Storz GmbH and Co. KG, Tuttlingen, Germany), ${ }^{5}$ which has been shown to be effective for difficult airway management, ${ }^{6}$ allows visualization of the glottic aperture and the trachea, and thus endotracheal tube placement under vision. Although the efficacy of the Bonfils intubation fibrescope has been demonstrated in patients with anticipated difficult airway based on predictors, ${ }^{7}$ its use has not been prospectively evaluated in patients with documented difficult airways. We tested the hypothesis that the rate of failed endotracheal intubation with direct laryngoscopy could be reduced with the Bonfils intubation fibrescope in patients with a difficult airway, simulated by means of a rigid cervical immobilization collar.

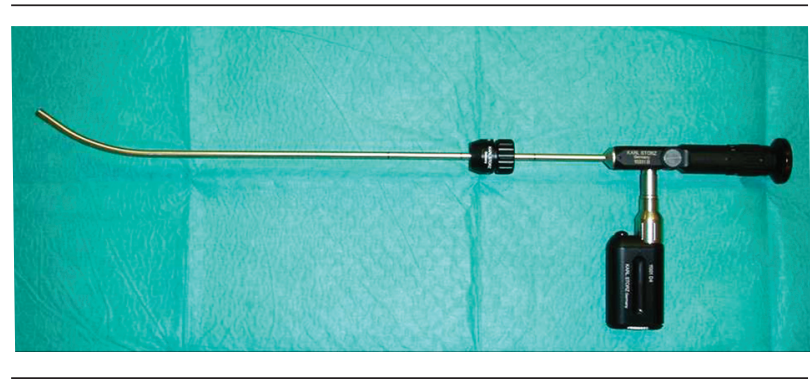

FIGURE 1 Bonfils intubation fibrescope with batterypowered light source attached. The fibrescope is a reusable, rigid, straight device with a $40^{\circ}$ curved tip, and a movable eyepiece mounted on the handle. The length is approximately $40 \mathrm{~cm}$, with an external diameter of $5 \mathrm{~mm}$. It Bonfils fibrescope is suitable for endotracheal tubes with an internal diameter $\geq 6.0 \mathrm{~mm}$ and a length $\leq 39 \mathrm{~cm}$.

\section{Methods}

After approval of the study protocol by the institutional Review Board, 76 adult patients undergoing elective gynecological surgery under general anesthesia were included in the study after informed, written consent was obtained. All patients underwent preoperative evaluation and thorough airway examination on the day before surgery. Those patients presenting with two or more predictors for difficult mask ventilation, ${ }^{8}$ difficult endotracheal intubation, or both, were excluded from the study. In addition, any patient with a history of difficult endotracheal intubation was excluded. A combination of at least two of the following factors was considered predictive for a potentially difficult airway: intraoral, pharyngeal, laryngeal or cervical masses, history of surgery in these regions, Mallampati class 3 or 4 , thyromental distance $<6.5$ $\mathrm{cm}$, neck extension $<30^{\circ}$, inter-incisor distance < $3.5 \mathrm{~cm}$, patients who were edentulous, patients with a beard, and patients with a history of snoring or obstructive sleep apnea.

Patients were randomly allocated to one of two groups, to receive endotracheal intubation, facilitated either by direct laryngoscopy with a size 3 Macintosh blade, or with the Bonfils intubation fibrescope. Allocation concealment was achieved with the use of coded, sealed, opaque envelopes, and randomization was established by simple shuffling of the envelopes. In the operating room, routine monitors were applied, and anesthesia was induced intravenously in all patients. Following verification of adequate bag-mask ventilation, neuromuscular blockade was achieved with cisatracurium $0.1 \mathrm{mg} \cdot \mathrm{kg}^{-1} i v$. A difficult airway was created with a cervical immobiliza- 
tion collar (Stifneck Select, Leardal Medical GmbH, Puchheim, Germany), the appropriate size being selected according to the manufacturer's instructions with the finger-sizing method. This device effectively downsizes mouth opening, and limits neck extension.

The Bonfils intubation fibrescope is a reusable, rigid, straight device with a $40^{\circ}$ curved tip, and a movable eyepiece mounted on the handle of the scope (Figure 1). The length is approximately $40 \mathrm{~cm}$, with an external diameter of $5 \mathrm{~mm}$. It is suitable for tracheal tubes with an internal diameter $\geq 6.0 \mathrm{~mm}$ and a length $\leq 39 \mathrm{~cm}$; thus, all standard single-lumen endotracheal tubes can be used without cutting them. The fibrescope carries a connector that fits onto the $15-\mathrm{mm}$ tracheal tube adapter, thereby allowing oxygen insufflation. A cold light source or a small battery handle, powered by two $1.5 \mathrm{~V}$ alkaline batteries, can be attached to the stylet handle. In contrast to a flexible fibrescope, the Bonfils intubation fibrescope does not have a working or suctioning channel. The scope is inserted from the right, alongside the patient's molars. A conventional size 3 Macintosh blade was simultaneously inserted with the operators' left hand to create sufficient retropharyngeal space (Figure 2 ). Guided by the operator's right hand, the Bonfils intubation fibrescope was advanced underneath the epiglottis, then carefully guided through the glottic aperture, until tracheal rings could be identified. The endotracheal tube was then inserted into the trachea under direct vision. A 7.0-mm internal diameter endotracheal tube, with an outer diameter of $9.6 \mathrm{~mm}$, was used in every instance (Lo-Contour ${ }^{\mathrm{TM}}$ Tracheal Tube, Nellcor, Pleasanton, CA, USA). All tracheal intubations were performed by a single operator, who had a experience with over 50 tracheal intubations using the Bonfils intubation fibrescope.

Before endotracheal intubation, all patients received bag-ventilation for three minutes with $100 \%$ oxygen. A maximum of two direct laryngoscopy attempts was carried out in patients assigned to undergo endotracheal intubation with a Macintosh blade. The same applied to the Bonfils group. Regardless of group allocation, intubation attempts were stopped either after $120 \mathrm{sec}$, or when oxygen saturation measured by pulse oximetry decreased below 92\%. In these cases, the cervical immobilization collar was removed and, after intermittent mask ventilation with $100 \%$ of oxygen, conventional direct laryngoscopy was performed with a standard size 3 Macintosh laryngoscope blade.

The primary outcome variable was success in correct endotracheal tube placement. Due to the nature of this study, the physician who performed the tracheal intubation was not blinded to the airway device being

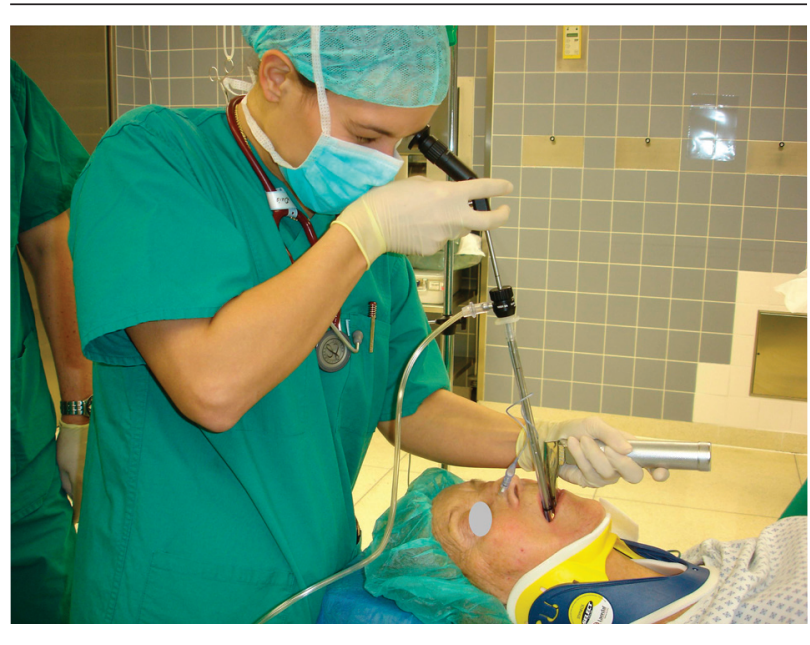

FIGURE 2 While sufficient retropharyngeal space is created with a size 3 Macintosh laryngoscope blade, the Bonfils intubation fibrescope loaded with an endotracheal tube is inserted from the right side of the patient's mouth, alongside the molars.

used. Secondary variables comprised the time required for endotracheal tube placement, defined as the interval between cessation of mask ventilation, until sufficient ventilation via the endotracheal tube was established (endtidal $\mathrm{CO}_{2} \geq 20 \mathrm{mmHg}$, endtidal volume $\geq 400 \mathrm{~mL}$ ). Furthermore, the best view obtained with direct laryngoscopy was rated according to the Cormack and Lehane scoring system ${ }^{9}$ as modified by Yentis and Lee: ${ }^{10} \mathrm{l}=$ full view of the glottis; $2 \mathrm{a}=$ partial view of the glottis; $2 b=$ arytenoids, or posterior portion of cords only visible; $3=$ only the epiglottis visible; $4=$ neither epiglottis nor glottis visible.

\section{Statistical considerations}

Sample size estimates suggested that 38 subjects per group would be needed to achieve $80 \%$ power to detect an absolute $35 \%$ reduction in the frequency of failed endotracheal intubation $(\alpha=5 \%)$. After Gaussian distribution of the raw data was confirmed, all data were summarized as mean \pm standard deviation, or numbers and per cent. Statistical analysis was carried out using a software package (GraphPad InStat Version 3.06; GraphPad Software Inc., SanDiego, CA, USA). Student's $t$ test was applied to the primary outcome, and Fisher's exact test was used where appropriate. Statistical significance was assumed with a probability of type I error less than $5 \%(P<0.05)$. 


\section{Results}

No patient had any predictors for a difficult airway, or a history of difficult intubation. No intubation attempt had to be aborted because of oxygen desaturation, and all 76 patients completed the study. A post-hoc analysis of the study data calculated $96.8 \%$ power $(\beta=0.032)$.

The groups were similar with respect to mean age, height, weight, and inter-incisor distance (Table). Endotracheal tube placement was successful in 15 (39.5\%) of 38 patients in the Macintosh group, and in $31(81.6 \%)$ of 38 patients in the Bonfils fibrescope group $(P=0.0003)$. However, two attempts were required in one patient of the Macintosh group, and in four patients of the Bonfils group. All patients in whom tracheal intubation failed with the immobilization collar in situ ( $n=30$ in total) had successful tracheal intubation with a standard size 3 Macintosh blade, after removal of the collar.

The distribution of patients, according to the best glottic view obtained during direct laryngoscopy, was as follows: grade $1(n=2)$; grade $2 \mathrm{a}(n=3)$; grade $2 \mathrm{~b}(n=14)$; grade $3(n=18)$; and grade $4(n=1)$. For all 31 patients in the Bonfils group whose tracheas were intubated successfully with the Bonfils device, a full view of the glottis (corresponding to Cormack and Lehane grade 1) could be obtained. Of remaining patients in the Bonfils group, lifting the epiglottis, and maneuvring the Bonfils device into the vallecula, failed in five subjects. In another subject, severe fogging of the lens obscured the view completely. For the one remaining patient in this group, a very tight fit of the cervical immobilization collar prevented any degree of mouth opening, and thus insertion of the Bonfils intubation fibrescope was impossible. The time required for successful endotracheal tube placement was 53 $\pm 22 \mathrm{sec}$ with the Macintosh blade, compared to 64 $\pm 24 \mathrm{sec}$ with the Bonfils intubation fibrescope $(P=$ $0.1508)$. No procedure-related complication, such as dental, lip, or airway injury, was observed in either group.

\section{Discussion}

In this study, the Bonfils intubation fibrescope was associated with a higher success rate of endotracheal tube placement compared to a standard size 3 Macintosh laryngoscope blade, in patients with simulated difficult airway. With the Bonfils intubation fibrescope, a trend towards a longer duration of endotracheal intubation was observed.

Bein et al. ${ }^{7}$ showed previously, that endotracheal tube placement is faster with the Bonfils fibrescope when compared to the intubating laryngeal mask
TABLE Demographic data and inter-incisor distancs

\begin{tabular}{lll}
\hline Group & $\begin{array}{l}\text { Macintosh blade } \\
(n=38)\end{array}$ & $\begin{array}{l}\text { Bonfils intubation fibrescope } \\
(n=38)\end{array}$ \\
\hline Age $(\mathrm{yr})$ & $44.2 \pm 19.3$ & $46.4 \pm 20.3$ \\
Height $(\mathrm{cm})$ & $168.2 \pm 7.0$ & $167.4 \pm 5.7$ \\
Weight $(\mathrm{kg})$ & $71.2 \pm 9.9$ & $69.3 \pm 8.3$ \\
BMI $\left(\mathrm{kg} \cdot \mathrm{m}^{-2}\right)$ & $25.2 \pm 3.4$ & $24.7 \pm 2.7$ \\
Inter-incisor & $2.6 \pm 0.7$ & $2.6 \pm 0.8$ \\
distance $(\mathrm{cm})$ & & \\
\hline
\end{tabular}

Data are expressed as mean \pm standard deviation. $\mathrm{BMI}=$ body mass index.

airway (ILMA), in patients with predicted difficult airway. The predictors of difficult airway included one or more of the following: Mallampati score $\geq 3$, thyromental distance $<6 \mathrm{~cm}$, inter-incisor distance $<$ $3.5 \mathrm{~cm}$, or mobility at the atlanto-occipital joint $<15^{\circ}$ according to Bellhouse and Dore. ${ }^{11}$ The median time to first ventilation was significantly shorter with the ILMA $(20 \mathrm{sec})$ in comparison with the Bonfils intubation fibrescope (40 sec). ${ }^{7}$ In contrast, the patients in our study had two strong predictors for difficult intubation after placing the rigid collar: inter-incisor distance $<3.5 \mathrm{~cm}$, and immobility at the atlanto-occipital joint. Despite this challenging airway presentation, adequate ventilation via the endotracheal tube was achieved in a mean times of $64 \pm 24 \mathrm{sec}$ and $53 \pm 22$ $\mathrm{sec}$, with the Bonfils intubation fibrescope and direct laryngoscopy, respectively. However, in contrast to Bein et al., ${ }^{7}$ who reported a $100 \%$ success rate in endotracheal intubation using the Bonfils intubation fiberscope, ${ }^{7}$ success was achieved in $82 \%$ of patients in our study. In another investigation, Bein et al. ${ }^{6}$ observed that endotracheal intubation was successful in $96 \%$ of patients, when the Bonfils intubation fibrescope is used in patients with an unanticipated difficult airway, after direct laryngoscopy had failed. ${ }^{6}$

The main reason for intubation failure with the Bonfils intubation fibrescope in our study was most likely due to an inability to direct the rigid device underneath the epiglottis, despite the application of external laryngeal pressure. Since the patients' heads were fixed in a neutral position, it remains speculative as to whether or not endotracheal intubation would have been successful with a certain degree of atlantooccipital joint mobility. It seemed likely, however, that this problem could have been overcome with greater curvature of the tip of the Bonfils device, e.g., $60^{\circ}$, instead of $40^{\circ}$. Unfortunately, the curvature of this device is fixed.

Lens fogging resulted in failed intubation in one patient of the Bonfils group. It is conceivable that 
storing the Bonfils intubation fibrescope in a warm location could reduce the incidence of lens fogging. Regardless of the fact that the tip of the Bonfils intubation fibrescope is placed inside the endotracheal tube, thus protecting the lens from soiling to a greater extend than with a flexible fibrescope, the use of the Bonfils fibrescope also requires a relatively "dry" airway. Its usefulness is therefore limited, in patients with blood and/or extensive airway secretions.

Difficult laryngoscopy (Cormack and Lehane grades 3 and 4), was reported in $64 \%$ of patients when the cervical spine was immobilized in a rigid collar, with sandbags placed on either side of the neck, and tape placed across the forehead. ${ }^{12}$ Using manual in-line stabilization of the cervical spine, difficult laryngoscopy with a Macintosh blade occurred in only 16-33\% of patients. ${ }^{13,14}$ This improvement in intubating conditions can be attributed to almost unrestricted mouth opening during manual in-line stabilization, compared to a substantively diminished inter-incisor distance when a rigid cervical collar is used. Therefore, manual in-line stabilization of the cervical spine simulates a difficult airway to a lesser extent than a rigid immobilization collar.

With the introduction of the ILMA in 1997, an alternative to direct laryngoscopy became available for patients with an unanticipated difficult airway. ${ }^{2}$ Several studies investigated the success of tracheal intubation with the ILMA in patients with cervical spine immobilization collars, however, their results were inconsistent. While tracheal intubation failed in $70 \%$ of patients in a study by Wakeling and Nightingale, ${ }^{15}$ Komatsu et al. ${ }^{16}$ reported a success rate of $96 \%$. In the latter study, inter-incisor distance was smaller in the study group $(4.1 \pm 0.8 \mathrm{~cm})$ than in the control group of subjects who had normal cervical spine clearance $(4.6 \pm 0.7 \mathrm{~cm})$. The clinical impact of this small but statistically significant difference is uncertain. In our study, inter-incisor distance was only $2.6 \pm 0.7$ $\mathrm{cm}$ in the Macintosh group, and $2.6 \pm 0.8 \mathrm{~cm}$ in the Bonfils group. These degrees of mouth opening were notably smaller than those reported in other randomized controlled trials. An inter-incisor distance which minimally exceeds the outer diameter of the corresponding endotracheal tube, when using the Bonfils fibrescope, is generally adequate when using this device. Supplementary insertion of a standard size 3 Macintosh blade to create sufficient retropharyngeal space for improved handling of the Bonfils intubation fibrescope, can be of additional benefit in patients with more restricted mouth opening. However, manipulating the Macintosh blade to obtain an improved laryngoscopic view that facilitates endotracheal tube placement, requires more oropharyngeal space.

One methodological weakness of this study is that the operating physician performing tracheal intubation, could not be blinded, according to the airway device being evaluated. While potential bias therefore exists with respect to both the primary and secondary outcomes of interest, the fact that the outcome measures were objective, minimizes the potential negative impact of lack of blinding procedures.

In conclusion, the Bonfils intubation fibrescope is an effective and safe intubating device for patients with an immobilized cervical spine associated with limited inter-incisor distance. Even though the success rate of endotracheal intubation was significantly higher compared to direct laryngoscopy, a failure rate of $18 \%$ was observed with the Bonfils intubation fibrescope. Nevertheless, after gaining familiarity with the Bonfils intubation fibrescope in patients with normal airways during elective procedures, physicians should consider this device in patients with anticipated difficult airways due to limited neck extension and mouth opening.

\section{References}

1 American Society of Anesthesiologists Task Force on Management of the Difficult Airway. Practice guidelines for management of the difficult airway: an updated report by the American Society of Anesthesiologists Task Force on Management of the Difficult Airway. Anesthesiology 2003; 98: 1269-77.

2 Brain AI, Verghese C, Addy EV, Kapila A, Brimacombe $J$. The intubating laryngeal mask. II: A preliminary clinical report of a new means of intubating the trachea. Br J Anaesth 1997; 79: 704-9.

3 Huang WT, Huang Cr, Chung YT. Clinical comparisons between GlideScope video laryngoscope and Trachlight in simulated cervical spine instability. J Clin Anesth 2007; 19: 110-4.

4 Agro F, Barzoi G, Mantecchia F. Tracheal intubation using a Macintosh laryngoscope or a GlideScope in 15 patients with cervical spine immobilization. $\mathrm{Br} \mathrm{J}$ Anaesth 2003; 90: 705-6.

5 Bonfils $P$. Difficult intubation in Pierre-Robin children, a new method: the retromolar route (German). Anaesthesist 1983; 32: 363-7.

6 Bein B, Yan M, Tonner PH, Scholz J, Steinfath M, Dorges $V$. Tracheal intubation using the Bonfils intubation fibrescope after failed direct laryngoscopy. Anaesthesia 2004; 59: 1207-9.

7 Bein B, Worthmann F, Scholz J, et al. A comparison of the intubating laryngeal mask airway and the Bonfils intubation fibrescope in patients with predicted difficult airways. Anaesthesia 2004; 59: 668-74.

8 Langeron O, Masso E, Huraux C, et al. Prediction of 
difficult mask ventilation. Anesthesiology 2000; 92:

1229-36.

9 Cormack RS, Lehane J. Difficult tracheal intubation in obstetrics. Anaesthesia 1984; 39: 1105-11.

10 Yentis SM, Lee DJ. Evaluation of an improved scoring system for the grading of direct laryngoscopy. Anaesthesia 1998; 53: 1041-4.

11 Bellhouse CP, Dore C. Criteria for estimating likelihood of difficulty of endotracheal intubation with the Macintosh laryngoscope. Anaesth Intensive Care 1988; 16: 329-37.

12 Heath KJ. The effect on laryngoscopy of different cervical spine immobilisation techniques. Anaesthesia 1994; 49: 843-5.

13 Laurent SC, de Melo AE, Alexander-Williams JM. The use of the McCoy laryngoscope in patients with simulated cervical spine injuries. Anaesthesia 1996; 51: $74-5$.

14 Smith CE, Pinchak AB, Sidhu TS, Radesic BP, Pinchak $A C$, Hagen $J F$. Evaluation of tracheal intubation difficulty in patients with cervical spine immobilization: fiberoptic (WuScope) versus conventional laryngoscopy. Anesthesiology 1999; 91: 1253-9.

15 Wakeling HG, Nightingale J. The intubating laryngeal mask airway does not facilitate tracheal intubation in the presence of a neck collar in simulated trauma. $\mathrm{Br} \mathrm{J}$ Anaesth 2000; 84: 254-6.

16 Komatsu R, Nagata O, Kamata K, Yamagata $K$, Sessler DI, Ozaki $M$. Intubating laryngeal mask airway allows tracheal intubation when the cervical spine is immobilized by a rigid collar. Br J Anaesth 2004; 93 : 655-9. 